\title{
Multichannel search patterns and webrooming behaviours in the service industries: the case of motor insurance
}

\author{
Tun-I Hu${ }^{1} \cdot$ Andrea Tracogna $^{1}$ (D) \\ Received: 27 October 2020 / Accepted: 17 February 2021 / Published online: 8 March 2021 \\ (c) The Author(s) 2021
}

\begin{abstract}
This article aims at analysing the empirical categories and the main determinants of channel choices in the contractualized individual services category, with particular reference to multichannel search patterns and webrooming behaviours, whereby customers search online but purchase offline (namely, at the service provider's premises). Based on an international survey of motor insurance customers, a set of hypotheses on the determinants of customers' shopping journeys, inclusive of search and purchase channel decisions, have been tested with a multinomial logistic regression. Our results show that channel choices-both relative to search and to purchase-are significantly influenced by the customer's preference for personal interaction (which typically favours the personal, offline, channels); overall, the relevance of channel choice determinants differs in the different shopping phases: indeed, while the search patterns (mono vs. multiple; digital vs. personal) are mainly determined by the customer need for information and by her/his preference for shopping innovation and enjoyment, the purchase channel choices are mainly driven by the customer's preference for service quality (personal purchase) and by his/her price consciousness (digital purchase). In particular, webrooming behaviours occur when a less price-conscious customer, after having actively explored multiple channels to satisfy the appetite for information, eventually prefers to purchase the service at the provider's physical store (i.e. the insurance agent) to satisfy his/her preference for personal interaction and service quality. These results shed light on multichannel behaviours in service industries and may help providers better inform the retail strategies of contractualized individual services.
\end{abstract}

Keywords Multichannel search · Channel choice · Research shopping · Webrooming $\cdot$ Motor insurance

Andrea Tracogna

andrea.tracogna@deams.units.it

1 Department of Economics, Business, Mathematics and Statistics (DEAMS), University of Trieste, Via dell'Università 1, 34123 Trieste, Italy 


\section{Introduction}

Multichannel behaviours are today informing the shopping of most goods and services, thus originating peculiar research shopping (Verhoef et al. 2007) and webrooming (Flavian et al. 2016; $\mathrm{Hu}$ and Tracogna 2020) phenomena, and namely the tendency of several customers to use one channel for search and another for purchase (research shopping) and their preference for looking at something to buy online and eventually purchasing it in a physical store (webrooming). According to the evidence provided by Flavian et al. (2019), webrooming is today the dominant cross-channel combination (the other combination being showrooming, i.e., the offline search followed by an online purchase), thus representing the most significant form of research shopping behaviour. This article aims at analysing the implications of multichannel shopping and webrooming behaviours within service industries, and namely for the contractualized individual services, and at identifying the most significant channel choice determinants; in doing so, a number of distinct patterns of customer search are here classified.

A better understanding of multichannel shopping behaviours is important for the service providers. Indeed, their huge efforts to widening the available channels and offering their customers the access to new digital channels may be often nullified or put at risk by the persistent preference, by the customer, to complete the purchase in the traditional channels. By leveraging on the actual preferences of their customers, service providers may better define their channel investments and develop more effective multichannel strategies, with the ultimate goal of maximizing the overall conversion rates from search to purchase. From an academic standpoint, our paper is aimed at filling a pending gap in the multichannel research. Indeed, in spite of the rich extant literature on the multichannel construct (of which we give a thorough account in the next Sect. 2), and of a broad understanding of their determinants and implications, including the research shopping and channel synergy phenomena, several aspects of customer multichannel behaviours in the service industries (as opposed to the shopping of goods) still require further investigation (Liu et al. 2018), while specific calls have been made for further studies considering channel choice decisions in multichannel environments, particularly aimed at investigating the interdependencies between the search and the purchase choices (Verhoef et al. 2007). Compared to previous studies on multichannel shopping, this paper focuses specifically on the services industries and introduces a thorough classification of search patterns and a comprehensive set of customer behaviour determinants, specifically at the psychographic level. In particular, this research represents an attempt to advance and generalize recent studies on the determinants of service shopping journeys in motor insurance (Hu and Tracogna 2020). A number of questions are driving this research: what are the factors driving the service customers' selection of search channels and orienting their preference for, either, a monochannel or a multichannel pattern of search? How do the different search patterns convert into specific purchase channel decisions? And what factors, in particular, explain customers' webrooming behaviours, i.e., their preference to finalize the purchase offline, e.g., at a physical store, despite having searched extensively online? 
This research is focused on the category of contractualized individual services, i.e., the services which are procured by individuals (and their families) on a continuous and contractual basis and which are reliant on an ongoing relationship between the provider and the customer (Lovelock 1983). Such category includes a broad range of services, from personal bank accounts to individual/retail insurance policies, personal mobile communication services, household electricity supplies and other utility services, among others. Our focus is justified in the light of the length and complexity of these service's customer journeys (which encompass several phases, from search to purchase and post-purchase) and of the number of service features which may favour multichannel and research shopping behaviours, including the typical indefinite duration of the service relationship (either because of the long-term extension of the contract or as a consequence of the several periodical renewals), the extended pre- and post-purchase interactions between the service provider and the customer (the parties initially get in contact to exchange information, and keep interacting to assure an effective administration and execution of the contract), the significant channel synergy effects (i.e., the customer's past search and purchase decisions and the whole service experience affect the successive channel decisions), and the significant efforts made by the service providers to escort the customer along the several phases of the journey, adopting sophisticated multichannel retail approaches which extend to both physical and digital channels. The above features are peculiar of contractualized services and clearly differentiate this unique category from the other services and from the shopping of goods.

The empirical focus of this study is motor insurance, which, based on their features, truly represent the whole contractualized services category, as it is characterized by repetitive purchases (with the customer having periodically, over the renewal "window", the possibility to change the policy elements, the search and purchase channel, and even the provider), by a significant post-purchase phase (signed by several possible interactions, including the reporting of an accident, the management of claims, and other customer-provider interactions) and by channel synergy effects (i.e., past channels exert an influence on the successive channel choices). Further, recent empirical studies show that the insurance markets significantly display webrooming behaviours (Barwitz and Maas 2018; Hu and Tracogna 2020) and a persistent preference, by the customers, to complete the purchase with the insurance agent (Insurance Europe 2019; Insurance Information Institute 2020). Thus, a better understanding of the determinants of multichannel shopping and webrooming behaviours in motor insurance may, on the one side, provide relevant insights for the improvement of the retail strategies of service providers and, on the other side, shed light on the whole category of contractualized individual services.

The paper has the following structure. In the second section, the studies on research shopping and webrooming behaviours are introduced and positioned within the larger literature on multi-/omnichannel shopping and retailing constructs. In the third section, a classification of customers' mono- and multiple-search patterns is provided, and our set of hypotheses on their determinants is proposed. In the fourth section, the methods, including the sampling and measurement procedures, of the empirical research are described. In the fifth section, an account is given of the empirical results, including the tests of the hypotheses with a (multinomial) 
regression model. The sixth section discusses our research findings and derives both academic implications and managerial insights for service providers, addressing a number of limitations, and providing some possible directions for future research.

\section{Background and literature review}

Multichannel search is here defined as the customer's simultaneous use, within the same shopping journey, of multiple channels of the similar type or as the simultaneous use of different channel types, with the aim of collecting the needed information on a good or service, before finalizing the purchase (Hu and Tracogna 2020). This definition, which mostly emphasizes the information search phase, is derived from and consistent with the broad extant academic literature on the multichannel construct (see Table 1, below). However, scholars haven't reached an early consensus on this definition: indeed, over the years, multichannel definitions have gradually shifted their focus from the purchase to the search phase. In the meantime, the gradual evolution of customers towards multichannel behaviours and the progressive development of new digital channels have broadened the multichannel phenomenon, thus opening the door to new constructs, such as those of omnichannel shopping and retailing. Overall, multi-/omnichannel shopping and retailing represent two sides of the same coin, where the customer triggers full channel interaction with the retailer and the retailer, in turn, aims at assuring full channel integration to offer the customer a consistent shopping experience (Beck and Rygl 2015). Within this perspective, search and purchase are not separate and independent, but rather complementary stages of the shopping journey. In Table 1, below, we provide an account of the evolution of the multichannel construct in the academic literature.

The multi- and omnichannel constructs have the merit to highlight the possibilities, for the customer and the retailer, to leverage on the many available search and purchase channels and to generate positive (synergy) effects. Channel synergy effects, whereby search (or purchase) attitudes on one channel may translate into preferences toward search (or purchase) on another channel, have been first described by Verhoef et al. (2007). Synergy effects may occur both contextually (same time, different products) and at the temporal level (same product, different times), where, in the latter case, the choice of a previous channel increases the chances of using that same channel again (Gensler et al. 2012; Piercy 2012). Verhoef et al. (2007) identify a channel lock-in (or spill over) effect-where the channel chosen in one stage of the shopping journey affects the likelihood of choosing that same channel in another shopping stage-and introduce the research shopper construct, which describes the propensity of consumers to research the product in one channel, and then purchase it through another channel. Within a research shopping framework, the interplay between physical (offline) and digital (online) channels may generate two opposite effects: "showrooming", whereby the information is collected offline while the purchase occurs online (Bell et al. 2014), with the online activities substituting for an experiential shopping in the physical store (Pauwels et al. 2011), and "webrooming" (Bell et al. 2017), whereby the customer collects the information online, but the purchase occurs offline. Several determinants of 
Table 1 Key definitions of multi- omnichannel shopping and retailing

\section{Author}

Multichannel shopper/customer

Schoenbachler and Gordon (2002)

Wind and Mahajan (2002)

Kumar and Venkatesan (2005)

Verhoef et al. (2007)

Weinberg et al. (2007), Cho and Workman (2011)

McGoldrick and Collins (2007)

Zhang et al. (2010)

Rippé et al. (2015)

Omnichannel shopper/customer

Piotrowicz and Cuthbertson (2014)

Juaneda-Ayensa et al. (2016)

Yurova et al. (2017)

Saghiri et al. (2018)
Definition

Multichannel consumers use the available channels according to their preferences, perceived convenience and product availability, which can be different along the shopping phases

Multichannel shopping behaviour is associated with the combination of various channels and approaches, such as searching online and buying offline, searching offline and buying online and everything in between

Multichannel shoppers are those customers who have made a purchase in more than one channel in an observed period of time

Research shoppers are those customers who research the product in one channel and then purchase it through another channel

Multichannel shoppers utilize a variety of different purchasing channels

Multichannel customers use a variety of channels to research their products, before committing to buy them

Multichannel shoppers use multiple channels along their shopping process

Multichannel shoppers are knowledgeable consumers who gain information about the product by surfing and switching between channels

Omnichannel customers move freely between the online channels, the mobile devices, and the physical store within a single shopping journey

Omnichannel customers use the new technologies to search for information, offer opinions, explain experiences, make purchases, and "talk to the brand", with the expectation to have a seamless experience across channels

Omnichannel shoppers are those who shop for products and services using more than one retail channel, such as brick-and-mortar retailers, catalogues, websites, mobile devices

Customer with an omnichannel approach can interact with the product and the firm in all ways and in all locations, while the borders between different channels become fuzzy, and consumers seamlessly move between the available channels, searching for information and making their purchase decisions through the channels that best optimize their purchase needs 
Table 1 (continued)

\section{Author}

Multi- omnichannel retailing

Stone et al. (2002)

Rangaswamy and Van Bruggen (2005)

Neslin et al. (2006)

Choi and Park (2006)

Weinberg et al. (2007)

Lee and Kim (2008)

Lewis et al. (2014)

Piotrowicz and Cuthbertson (2014)

Verhoef et al. (2015: p.176)

Frasquet and Miquel (2017), Wollenburg et al. (2018)
Definition

Multichannel retail strategy is the management of customers in a way that is consistent and coordinated across all the channels used

Multichannel retailing shall provide consumers with information, products, services, support, and any kind of combinations through two or more synchronized channels

Multichannel retailing is the design, development, coordination, and evaluation of channels to enhance customer value through effective customer acquisition, retention, and development

Multichannel retailing is a distribution strategy to serve customers using more than one selling channel or medium

Multichannel retail strategy shall enable companies to offer customer services across different channels, thus building strong relationships with customers, improving the retention of the existing customers, and attracting new ones

Multichannel retailing is a model in which retailers use a combination of integrated channels to sell products and services to customers

Omnichannel retailing is aimed at delivering a seamless customer experience regardless of the channel

Omnichannel retailing is "the synergetic management of the numerous available channels and customer touchpoints, in such a way that the customer experience across channels and the performance over channels is optimized"

In multichannel retailing, diverse channels are managed so as to offer shoppers a seamless experience across all channels. In omnichannel retailing, neither the customer nor the retailer distinguishes between channels any longer

webrooming behaviours are reported in the literature. Schroder and Zaharia (2008) claim that webroomers combine the benefits of information search at online stores with low risk buying at physical stores. Chou et al. (2016) posit that the perceived risks associated with the purchase make the online search an important precursor to webrooming behaviour. Flavian et al. (2016) also argue that the motivation of online information search, before purchasing offline, is due to the online accessibility of the product reviews, which make consumers feel confident to buy in a physical store. The authors also point at the need-for-touch as a direct determinant of webrooming effects. Low switching costs, or the lack of lock-in, typical of online channels, 
could also push webrooming (Fornari et al. 2016). The better service quality offered by physical stores also acts as an antecedent to webrooming behaviours (Chiu et al. 2011).

Although the above studies have significantly advanced our understanding of the determinants of customers' shopping journeys and of multichannel choices, and have provided interesting insights on the determinants of research shopping behaviours and their implications for retailers and for the retail strategies, we believe there is still a need to further investigating the complex interdependencies between the search and the purchase channel decisions, with a particular focus on the relatively under investigated category of contractualized services. In so doing, we need a specific classification of search patterns and a number of determinants of channel choices, which we introduce in the next section, where our research model is described.

\section{Search pattern classification and hypotheses development}

Numerous search channel options are today simultaneously available to customers of different markets and industries. Due to this variety, any classification of channels may be partial and arbitrary. In the light of our research focus (contractualized individual services) and aims (identification of the determinants of search patterns), we have resorted not to clustering the search channels into the typical online (digital) and offline (physical) categories, but rather to adopt a slightly different classification, based on the channel's intensity of interaction, at the personal level, between the service provider and the service customer. Thus, we have distinguished between the "digital" channels and the "personal" channels. This distinction reflects the different features of the channels in allowing for a customer interaction with the sales organization (i.e., the service provider) at a personal level (i.e., face to face, verbally, via written individual communications) rather than impersonally (i.e., through generic interactions with the company, usually mediated by digital technologies) (Hu and Tracogna 2020). Indeed, based on the relational nature of contractualized services and depending on the customer's personal preferences and/or situational conditions, individuals may opt for the search channels offering more personal interaction-such as the service provider's store, the service provider's call centre and their personal acquaintances (family, friends, colleagues, and other close personal contacts)—and/or utilize more impersonal (digital) channels, such as the corporate websites, the corporate mobile apps, the web aggregators, and the digital social networks (mainly of corporate and independent nature). More specifically, for our classification purposes (digital vs personal channels) the "digital social networks" channel refers to the online collection of independent information on the product/service, both of corporate and independent origin; while the "friends and other personal contacts" channel refers to the personal interactions aimed at exchanging and generating product/service information through the customer's personal contacts, via any social relation and/or network. In addition, we observe that, differently than for the final purchase decisions, where only one channel will be eventually selected, 
the number of channels available for information search is virtually unlimited. In other words, consumers can search for information from one, two, or more channels, of the same or different type, until the needed information has been obtained. In sum, based on the preference for channel types (personal or digital) and on the number of channels actually utilized, we have identified five distinct search patterns of contractualized services:

1. Monochannel personal search where, within a specific shopping journey, the customer searches for information from only one personal channel.

2. Monochannel digital search where, within a specific shopping journey, the customer searches for information from only one digital channel.

3. Multichannel personal search where, within a specific shopping journey, the customer searches for information from more than one channel, but only within the personal category.

4. Multichannel digital search where, within a specific customer journey, the customer searches for information from more than one channel, but only within the digital category.

5. Multichannel mixed search where, within a specific customer journey, the customer searches for information from more than one channel, both within the personal and the digital category.

The aim of this research is to identify the main determinants of the above search patterns and, further, to explain what drives the conversion of a specific search pattern into a specific purchase channel decision. In line with these aims, and based on the broad stream of academic literature on channel choices in a multichannel perspective and on the determinants of shopping behaviours (Arora and Sahney 2019; Flavian et al. 2016, 2020; Konus 2008; Venkatesan et al. 2007; Verhoef et al. 2007), a set of seven hypotheses on the determinants of customers' patterns of search has been developed. All the psychographic variables we have selected refer to the general shopping attitudes of customers and not to their specific preferences and choices concerning the channels available, which-within our research design-represent, instead, our dependent variable.

The first two hypotheses are aimed at explaining a customer's preference towards the personal channels, irrespective of the adoption of a monochannel or a multichannel search pattern. Two determinants are here considered: the preference for service quality and the preference for personal interaction.

A preference for service quality is expressed by the customer when he/she expects to be supported and guided along the different shopping stages by the retailer itself (Parasuraman et al. 1988). This construct is related with what Baker et al. (2002) label as "interpersonal service quality", to indicate the quality of the interactions between store employees and the customers. Verhoef et al. (2007), in turn, define it as the consumers' perception of the delivered channel service, including the perception of obtaining good support and shopping advice. Based on the above definitions of service quality, it is just natural to make some basic assumptions on the different capacity of the different channels to satisfy the 
customer's preference for service quality. Indeed, although this preference can be satisfied through digital channels (Malhotra and Kubowitz-Malhotra 2013), we expect that a higher service quality (i.e., a customized service), will be more likely obtained through a personal channel, rather than a digital one. Then, the following hypothesis is derived:

H1 Customers with a higher preference for service quality will be more likely to search on personal channels, either via mono or multiple search patterns.

In the context of service shopping behaviours, the preference for personal interaction (Hu and Tracogna 2020) reflects the customer's desire to interact with the sales organization (i.e., the service provider) at a personal level (i.e., face to face, verbally, via written individual communications) rather than impersonally (i.e., through generic interactions with the company, usually mediated by digital technologies). The construct is closely aligned to the "need for interaction with a service employee" (Dabholkar 1996; Dabholkar and Bagozzi 2002) which has been defined as the importance of human interaction to the customer in service encounters. The expectation is here that customers showing a higher preference for personal interaction will first and mostly search from the personal channels rather than the digital ones (Florenthal and Shoham 2010). Thus, the following hypothesis is derived:

H2 Customers with a high preference for personal interaction will be more likely to search on personal channels, either via mono or multiple search patterns.

The next three variables (need for information, price consciousness, shopping intensity) are specifically aimed at explaining a customer's preference for a mono vs. a multichannel search pattern.

Need for information. Along their shopping journeys, service customers feel the need to collect information on service features, prices, reviews, methods of payment, and the available purchase alternatives. The capacity of a channel to provide the above information is an important determinant of channel choice (Choudhury and Karahanna 2008), i.e., the channels providing information in the right quality, quantity, and accessibility would be preferred by consumers (Alba et al. 1997; Hoque and Lohse 1999; Ratchford et al. 2001; Verhoef et al. 2007). Thus, it is argued thatdepending on their need for information-customers will prefer to search from multiple channels, as opposed to just one single channel. Furthermore, as information can be collected from both personal and digital channels, consumers with higher needs for information would use any available channels, irrespective of their type. The following hypothesis is derived:

H3 Customers with higher needs for information will be more likely to search from multiple channels, either of personal, digital or mixed categories. 
Price consciousness has been defined by Lichtenstein et al. (1990) as the consumer's degree of preference for buying at low prices: i.e., the higher the price charged, the less likely for a channel to be selected (Balasubtamanian et al. 2005; Gensler et al. 2012; Konus et al. 2008; Venkatesan et al. 2007; Verhoef et al. 2007). Although this preference may more easily be associated with the purchase choices, we here expect that, driven by the aim of paying the lowest prices, service customers will prefer searching on multiple channels, irrespective of the type, rather than limiting their search on just one channel (type). Then, the following hypothesis is derived:

H4 Customers with high price consciousness will be more likely to search from multiple channels, either of personal, digital or mixed categories.

Shopping intensity. This variable refers to the customer's entire shopping activity, and is not limited to the specific service at stake, as suggested instead by Chiou and Pan (2009). We define it as the customer's perceived level of intensity in his/her overall shopping activities, ranging from low intensity (light shopper) to high intensity (heavy shopper). The expectation is that this intensity (may increase the skills, the experience, and the confidence of a customer to use multiple search channels for his/her shopping purposes; as such, this variable is expected to be associated with multichannel search patterns: i.e., a heavy shopper will likely search for information from multiple channels, while a light shopper will likely search just on one or a few channels. Thus, the following hypothesis is derived:

H5 Customers with high shopping intensity will be more likely to search from multiple channels, either of personal, digital or mixed categories.

The last two hypotheses are aimed at explaining a customer's preference towards the digital vs the personal channels, in association to their preference for the multiple channel search patters. Two determinants are here considered: the shopping enjoyment and the preference for shopping innovation.

Shopping enjoyment is the fun and excitement that derives to the customer from his/ her peculiar shopping experiences (which may include, for instance, the customized service design) and from a personally enriching shopping process (Forsythe et al. 2006). Verhoef et al. (2007) have shown that there is an empirical association between this shopping preference and multichannel choices. Konus et al. (2008) also pointed at the fact that consumers who enjoy shopping are willing to spend more time during the shopping process, including the search for information from a variety of channels. Capitalizing on these findings, we here expect that a service customer's preference for shopping enjoyment, other than favouring a multichannel approach, can drive to the utilization of digital channels, which may offer customers a fun, enriching and exciting search experience. The following hypothesis is derived: 
H6 Customers with a higher preference for shopping enjoyment will be more likely to search from digital multiple channels.

Shopping innovation is defined as the customer's preference to try new and different products or channels and, in so doing, seek out new experiences (Midgley and Dowling 1978). According to Goldsmith and Hofacker (1991), shopping innovators are the first to know of a new product, to buy it, and to report to others about it. Within this research context (service channel choices), we follow Konus et al. (2008) who link shopping innovation to the selection of channels and posit that consumers with a high preference for innovation would search more extensively. Along the same line, Juaneda-Ayensa et al. (2016) also maintain that innovative customers show a stronger propensity to search on multiple channels. Leveraging on the above findings, we also expect that shopping innovation preferences may be better satisfied by the digital channels, which today represent-by themselves-an innovative shopping alternative, as compared to the traditional personal channels. The following hypothesis is derived:

H7 Customers with a high preference for shopping innovation will be more likely to search from digital multiple channels.

In the following Fig. 1 our research model and the hypotheses are visualized.

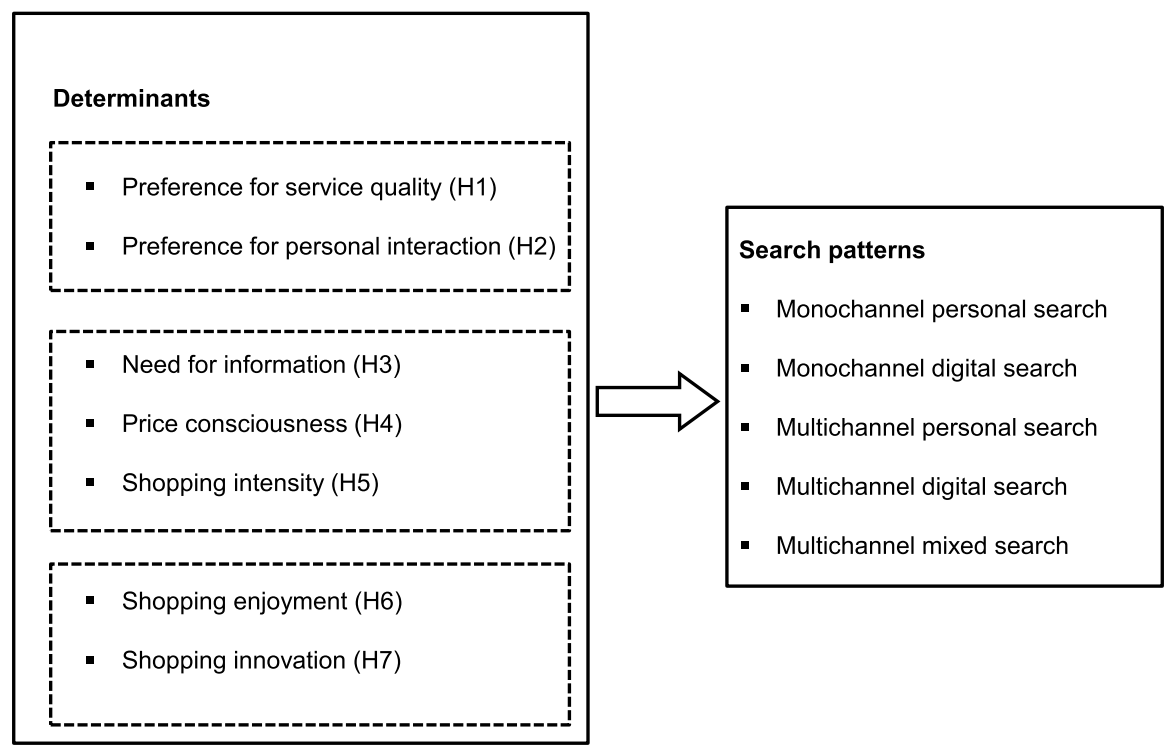

Fig. 1 Research model 


\section{Data collection and measurements}

\subsection{Data collection}

Our set of hypotheses have been tested through a web-based survey on a population of motor insurance customers. The survey has been carried out in the period January-February 2019. The target population was represented by the Masters' graduates of an Italian business school receiving their degrees in the 1991 to 2018 period. Respondents were required to self-assess on the set of variables described in the previous section. Further, assuming a reduced recall bias-based on the assumption that consumers recall past decisions beyond the current shopping choices (Bühler et al. 2016; Crosby et al. 1990)_respondents were asked to report both their current (T1) and their previous year (T0) search and purchase channels. The questionnaire has been designed, written and delivered in English, as all the respondents know English in a recognized level, being their degrees fully taught in this language. Based on the nature of the service (motor insurance), a few filter questions were aimed at avoiding any non-qualified responses (e.g., when the insured car is not owned by the individual, but by the employer who also decides the insurance coverage). Out of a sampling population of 2950 individuals, 554 questionnaires have been filled (fully or partially), with a $18.8 \%$ gross response rate. After cleaning the dataset from the non-qualified and incomplete responses, 338 complete questionnaires could be used for data analysis, representing a net response rate of $11.5 \%$. The profiles of the sampling population and of the sample of respondents are compared in Table 2.

\subsection{Measurements}

The dependent variable of this study are the search channel patterns actually utilized by the insurance customers along their service shopping journeys. Respondents were allowed to report more than one search channel, including the one selected for purchase (and namely, one of the following: insurance agent, corporate call centre, corporate website, corporate mobile app, and web aggregator) and also two informal channels: "digital social networks" (including the corporate social networks, the online reviews and other independent contents available online on products/ services) and "Friends and other personal contacts". For our classification purposes (described in Sect. 3 above), agents, corporate call centres and friends and other personal contacts have been included in the personal channels category, while corporate

Table 2 Profile of respondents

\begin{tabular}{lll}
\hline & Sampling population & Respondents \\
\hline$N$ & 2950 & 338 \\
Male & $1790(60.7 \%)$ & $238(70.4 \%)$ \\
Female & $1160(39.3 \%)$ & $100(29.6 \%)$ \\
Average age & 38 & 40 \\
\hline
\end{tabular}


websites, corporate mobile apps, web aggregators and digital social networks have been included in the digital channels category. Respondents had also the option to report another channel category ("Other") to include any other (or doubtful) experienced case. The few cases of use of this residual option have been carefully considered and reclassified, one by one, and included, in most cases, in the previous channels.

With reference to the independent variables, our multi-item scales have been derived from previous empirical studies on the multichannel search construct (Konus et al. 2008; Verhoef et al. 2007). With reference to the new constructs, the preference for personal interaction was measured through a multi-item scale composed of the following propositions: When shopping, I like to deal with a human. When shopping, I like to have a personal interaction with the seller. When shopping, I like to interact face to face. Shopping intensity has been measured with a one item scale, with the answers ranging from 1 ("I am a light shopper") to 5 ("I am a heavy shopper").

To validate the scales for all the independent variables, a principal-components analysis was carried out to examine if items are grouped to the corresponding variables and if the number of components is the same as the variables. 26 items from the 6 multi-item variables were considered for validation. Principal components have been extracted based on eigenvalues greater than 1. In total, as expected, 6 components were obtained, with a total variance explained of $68 \%$. To avoid or reduce collinearity between variables, components were rotated orthogonally through a Varimax method with Kaiser normalization. Composite reliability value (CR) and average variance extracted (AVE) were also calculated (Hair et al. 2016). Factor loadings above 0.5, Cronbach's Alphas exceeding 0.7, AVE above 0.5 and CR values above 0.7 have been recorded (Fornell and Larcker 1981; Nunnally and Bernstein 1994). Table 3 shows the correlation matrix for the above described construct validity tests.

Five control variables, aimed at capturing the whole channel experience of motor insurance customers along their last completed shopping journey (T0), were included in the dataset. These variables are the "cost of the insurance policy at the previous period (T0)" (namely, its natural logarithm), the "reporting of an accident" (a binary variable reporting when the insured car was subject to a damage claim in the previous period), the "change of the insured car" (a binary variable reflecting the case that the insured car has been changed from the previous to the current period). Age and gender have also been included, as control variables, in the regression models.

\section{Results}

Table 4, below, shows motor insurance policyholders' channel preferences (search and purchase) in the current insurance period (T1).

The table shows that the motor insurance is mainly purchased from an insurance agent, with percentages above $54 \%$, followed by corporate websites, online aggregators and providers' call centres $(22.8 \%, 13.3 \%$ and $8.6 \%$, respectively). As far as 


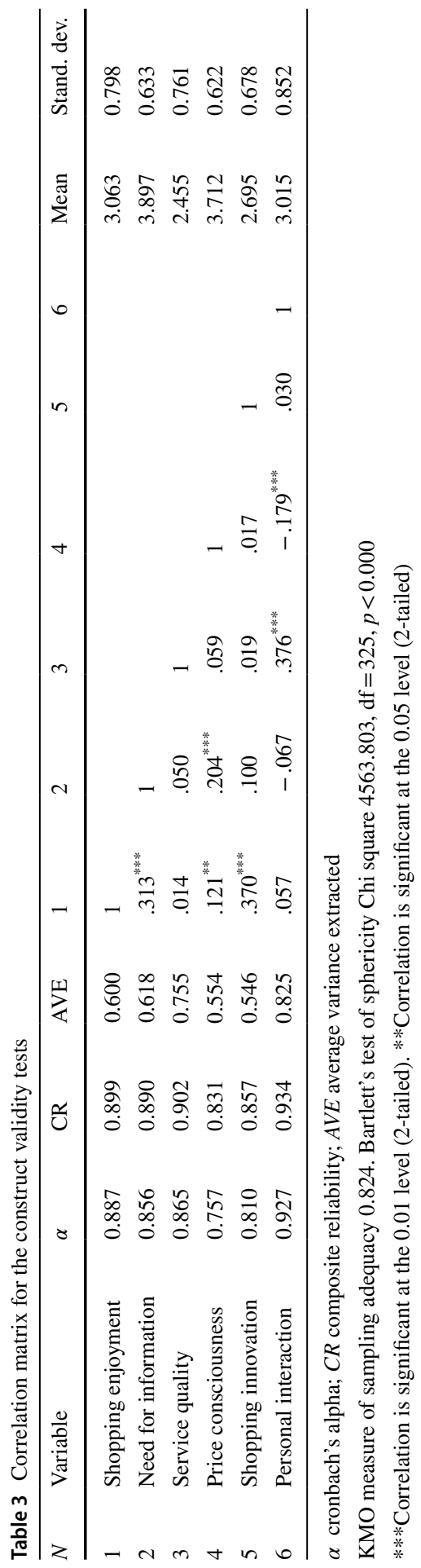


Table 4 Search and purchase channels at $\mathrm{T} 1$ and search-to-purchase conversion rates $(\mathrm{N}=338)$

\begin{tabular}{|c|c|c|c|c|c|c|c|c|c|c|c|c|c|c|}
\hline & \multicolumn{2}{|c|}{ Agent } & \multicolumn{2}{|c|}{$\begin{array}{l}\text { Corporate } \\
\text { call centre }\end{array}$} & \multicolumn{2}{|c|}{$\begin{array}{l}\text { Corporate } \\
\text { website }\end{array}$} & \multicolumn{2}{|c|}{$\begin{array}{l}\text { Corporate } \\
\text { mobile } \\
\text { app }\end{array}$} & \multicolumn{2}{|c|}{$\begin{array}{l}\text { Web } \\
\text { aggrega- } \\
\text { tor }\end{array}$} & \multicolumn{2}{|c|}{$\begin{array}{l}\text { Digital } \\
\text { social } \\
\text { networks }\end{array}$} & \multicolumn{2}{|c|}{$\begin{array}{l}\text { Friends } \\
\text { and other } \\
\text { personal } \\
\text { contacts }\end{array}$} \\
\hline & $N$ & $\%$ & $N$ & $\%$ & $N$ & $\%$ & $N$ & $\%$ & $N$ & $\%$ & $N$ & $\%$ & $N$ & $\%$ \\
\hline Search channel & 217 & 64.2 & 61 & 18.1 & 200 & 59.2 & 45 & 13.3 & 201 & 59.5 & 36 & 10.7 & 128 & 37.9 \\
\hline Purchase channel & 183 & 54.1 & 29 & 8.6 & 77 & 22.8 & 4 & 1.2 & 45 & 13.3 & & & & \\
\hline Conversion rate & & 84.3 & & 47.5 & & 38.5 & & 8.9 & & 22.4 & & & & \\
\hline
\end{tabular}

search channels are concerned, the data show two interesting features: on the one side, the tendency of most customers to use multiple search channels (overall, an average of 2.63 types of channels and more than 4 distinct channels have been used, for information search), and, on the other side, the different attitudes of the search channels to drive the purchase channel choices. Indeed, conversion rates from search to purchase significantly differ in the different channels, with some channels only used for search (such as friends/personal contacts, and online independent contents), others displaying a low conversion rate (such as the web aggregators and the mobile apps), and a few offline channels (namely, the insurance agencies) showing impressively high conversion rates (above $80 \%$ ), thus highlighting a peculiar webrooming effect.

Table 5, below, classifies the collected cases in one of the five search patterns introduced in Sect. 3.

A majority of customers are adopting a multiple search behaviour (277 out of 338, i.e., $82 \%$ ), while most of the multiple search customers adopt a mixed search pattern (more than $53 \%$ of the total cases).

Our seven hypotheses on the determinants of search behaviours have been put at test through a multinomial logistic regression, using the search patterns as the dependent variable, and the monochannel search patter as the reference category. The results of the regression are displayed in Table 6, below.

In testing our hypotheses, we have considered both the significance of the regression coefficients and the direction of the association (as reflected in the Exp (B)

Table 5 Channel search categories

\begin{tabular}{|c|c|c|c|c|c|}
\hline & & $N$ & & Percent & \\
\hline \multirow[t]{3}{*}{ Monochannel search } & & 61 & & $18.0 \%$ & \\
\hline & Monochannel personal search & & 45 & & $13.3 \%$ \\
\hline & Monochannel digital search & & 16 & & $4.7 \%$ \\
\hline \multirow[t]{4}{*}{ Multichannel search } & & 277 & & $82.0 \%$ & \\
\hline & Multichannel personal search & & 36 & & $10.6 \%$ \\
\hline & Multichannel digital search & & 60 & & $17.8 \%$ \\
\hline & Multichannel mixed search & & 181 & & $53.6 \%$ \\
\hline
\end{tabular}


Table 6 Channel search patterns and their determinants: multinomial logistic regression $(\mathrm{N}=338)$

\begin{tabular}{|c|c|c|c|c|c|c|c|c|}
\hline & \multicolumn{2}{|c|}{$\begin{array}{l}\text { Monochannel } \\
\text { Digital search } \\
(N=16)\end{array}$} & \multicolumn{2}{|c|}{$\begin{array}{l}\text { Multichannel } \\
\text { Personal search } \\
(N=36)\end{array}$} & \multicolumn{2}{|c|}{$\begin{array}{l}\text { Multichannel Digi- } \\
\text { tal search }(N=60)\end{array}$} & \multicolumn{2}{|c|}{$\begin{array}{l}\text { Multichannel } \\
\text { Mixed search } \\
(N=181)\end{array}$} \\
\hline & Sig. & $\operatorname{Exp}(B)$ & Sig. & $\operatorname{Exp}(B)$ & Sig. & $\operatorname{Exp}(B)$ & Sig. & $\operatorname{Exp}(B)$ \\
\hline Intercept & 0.749 & & 0.486 & & 0.206 & & 0.015 & \\
\hline Age & 0.670 & 0.462 & 0.252 & 0.224 & 0.367 & 0.331 & $0.009 * * *$ & 0.069 \\
\hline Gender & $0.034 * *$ & 5.358 & 0.569 & 1.339 & $0.003 * * *$ & 4.446 & $0.070 *$ & 2.048 \\
\hline Service quality & 0.448 & 0.776 & 0.719 & 0.923 & 0.109 & 0.709 & 0.474 & 0.880 \\
\hline Personal interaction & 0.160 & 0.634 & $0.044 * *$ & 1.632 & $0.029 * *$ & 0.614 & 0.498 & 0.883 \\
\hline Need for information & $0.093 *$ & 0.580 & 0.809 & 1.058 & $0.091 *$ & 1.453 & $0.026^{* *}$ & 1.491 \\
\hline Price consciousness & 0.710 & 0.891 & 0.420 & 1.215 & 0.227 & 1.301 & 0.897 & 1.024 \\
\hline Shopping intensity & 0.566 & 1.288 & 0.942 & 1.024 & 0.774 & 0.916 & $0.055^{*}$ & 1.636 \\
\hline Shopping enjoyment & 0.990 & 1.005 & 0.141 & 1.524 & $0.057^{*}$ & 1.652 & 0.118 & 1.409 \\
\hline Shopping innovation & $0.039 * *$ & 1.902 & 0.761 & 1.081 & 0.510 & 1.159 & 0.139 & 1.326 \\
\hline Purchasing cost at T0 & 0.286 & 0.673 & 0.540 & 1.271 & 0.225 & 0.705 & 0.953 & 0.984 \\
\hline $\begin{array}{l}\text { Change of car from } \\
\text { T0 to T1 }\end{array}$ & 0.813 & 1.246 & 0.845 & 1.134 & 0.374 & 1.673 & 0.643 & 1.259 \\
\hline $\begin{array}{l}\text { Reporting of an } \\
\text { accident at T0 }\end{array}$ & $0.090 *$ & 0.148 & 0.705 & 0.815 & $0.048 * *$ & 0.331 & 0.781 & 0.892 \\
\hline
\end{tabular}

Reference category: Monochannel personal search $(N=45), \quad-2 \log$ Likelihood=769.955, ChiSquare $=103.911$, Sig. $=0.000$

*Coefficient is significant at the 0.10 level (2-tailed). **Coefficient is significant at the 0.05 level (2-tailed). $* * *$ Coefficient is significant at the 0.01 level (2-tailed)

coefficients: below or above 1.00). We observe that no significant associations have been reported between the search patterns, the need for service quality and the level of price consciousness. In other words, these variables seem not to produce an effect on the customers' preferred search patterns. Thus, $\mathrm{H} 1$ and $\mathrm{H} 4$ are not supported by our data. In relation to a monochannel personal search (the reference category of our regression model), our results show that any increase in the preference for personal interaction is significantly and positively associated with a multichannel personal search, and negatively linked to a multichannel digital search. This is supporting $\mathrm{H} 2$ (i.e., customers with a high preference for personal interaction are expected to search from personal channels). Further, our results show that the need for information is positively associated with multichannel digital search and with multichannel mixed search, and negatively associated with a monochannel digital search, thus supporting H3 (i.e., customers with higher needs for information are expected to search from multiple channels). Furthermore, a positive association of shopping intensity with the multichannel mixed search pattern has been detected, thus supporting H5 (i.e., customers with high shopping intensity are expected to adopt multiple, rather than mono, search patterns). Our results also show that any increase in the need for shopping enjoyment is positively associated with a multichannel digital search behaviour. This is supporting H6, as customers driven by the need for shopping enjoyment would rather prefer to use multiple digital channels, as opposed to 
multiple personal channels. Finally, the data shows that the preference for shopping innovation is positively associated with a monochannel digital search (as opposed to monochannel personal search). Thus, H7 is also supported, although partially, as we couldn't detect a significant positive association with the multichannel digital search patterns. With reference to the control variables, our regression results show a negative association of the reporting of an accident in the previous period (T0) with both the mono- and the multichannel digital search. Further, results show a significant and negative association between age and multichannel mixed search and a strong association of digital search with gender (male customers show a higher tendency to search on digital channels). In sum, hypotheses H2, H3, H5, H6, H7 are supported by the data-although some significance levels fall between 5 and 10\% (2-tails)while $\mathrm{H} 1$ and $\mathrm{H} 4$ (on service quality and price consciousness, respectively) do not find support.

The last part of this study was aimed at identifying the factors which determine the customers' decisions where to finalize the purchase. It is at this stage, indeed, that a peculiar webrooming behaviour is displayed in the motor insurance markets. As can be observed from Table 7, 71.8\% (130 out of 181) of mixed search multichannel customers (those customers who simultaneously search on the digital and personal channels) finalize their purchase on the personal channels (agents and corporate call centres). This peculiar webrooming effect is significantly more pronounced than the opposite showrooming behaviour (28.2\%). The customers' preference for purchasing on the personal channels is clear and uncontroversial: after having searched through several different channels, and even after resorting to utilize a variety of sophisticated digital channels, most insurance customers prefer buying motor policies from the traditional personal channels (and namely from their agents).

To further investigating this webrooming tendency and to identifying the possible determinants of these peculiar behaviours, the sample of insurance customers has been split into two clusters: the first $(211$ cases, $62,4 \%)$ is represented by those customers that - in the last observed period (T1) - have purchased their motor policy on a personal channel (agent, call centre) and the second (127 cases, 37,6\%) by those customers that in $\mathrm{T} 1$ have purchased, instead, through a digital channel (corporate web site, web aggregator, mobile app). Our aim was to identify the main

Table 7 Search and purchase patterns at T1

\begin{tabular}{llll}
\hline & \multicolumn{2}{l}{ Purchase channel at T1 } & \\
\cline { 2 - 4 } & Personal purchase & Digital purchase & Total \\
\hline Monochannel digital search & 0 & 16 & $16(4.7 \%)$ \\
Monochannel personal search & 45 & 0 & $45(13.3 \%)$ \\
Multichannel personal search & 36 & 0 & $36(10.7 \%)$ \\
Multichannel digital search & 0 & 60 & $60(17.8 \%)$ \\
Multichannel mixed search & 130 & 51 & $181(53.5 \%)$ \\
Total & $211(62.4 \%)$ & $127(37.6 \%)$ & $338(100 \%)$ \\
\hline
\end{tabular}


determinants of purchase channel choices and to compare them with the determinants of the search patterns. A series of t-tests on the mean values of the covariates have been run, including the control variables and the purchase channel families at the previous period (T0). The results are reported in Table 8, below.

Results show that the finalization of the purchase within a personal channel is mostly associated with the customer's preference for personal interaction and for service quality, while the customers' price consciousness is associated with a digital finalization of the purchase. In sum: it is the combination of the preference for personal interaction and for service quality and the customer's low levels of price consciousness which ultimately determine the peculiar webrooming behaviours observed in the motor insurance markets. In particular, webrooming behaviours occur when a less price-conscious customer, after having actively explored multiple channels to satisfy the appetite for information, eventually prefers to purchase the service at the provider's physical store (i.e. the insurance agent) to satisfy his/ her preference for personal interaction and service quality. These findings highlight a fundamental difference in the determinants of search and purchase channel choices. Indeed, despite their significance for the search channel decisions, the need for information and the preference for shopping enjoyment don't show a significant and sizeable effect on the purchase channel selection. In other words, it is mostly at the search level that the need for information and the preference for shopping enjoyment are satisfied, while the purchase decisions are mostly driven by the customer's desire to receive a high service quality and to engage in a rich personal interaction. As regards the control variables, it is also to be noted that the selection of a personal purchase channel, differently than for the search channels, is positively associated with the reporting of an accident in T0 (which has been traditionally managed by an insurance agent) and with a higher cost of the policy at T0. However, the most significant determinant of purchase channel decisions at T1 is represented by the purchase channel (digital vs. personal) at T0, which highlights a very strong purchase channel synergy at the temporal level (from T0 to T1).

\section{Discussion and conclusions}

This research was aimed at shedding further light on multi- (and mono-) channel search patterns and their determinants in the service industries, and at analysing the relatively under-investigated webrooming behaviours in these markets. Our findings provide clear evidence that most service customers utilize multiple search channels, either digital or personal (or both), before making their purchase decisions. At the same time, our collected evidence also highlights that a nonnegligible fraction of insurance customers still adopt monochannel search patterns. Following our classification, these behaviours fall into one of five different patterns, which in turn have different determinants. Based on the tests carried out on our set of hypotheses, the selected search patterns (either personal or digital; mono or multiple, or hybrid) reflect the customer preference for personal interaction with the seller, the need for information, his/her preference for shopping enjoyment and for shopping innovation, and his/her overall shopping intensity. 


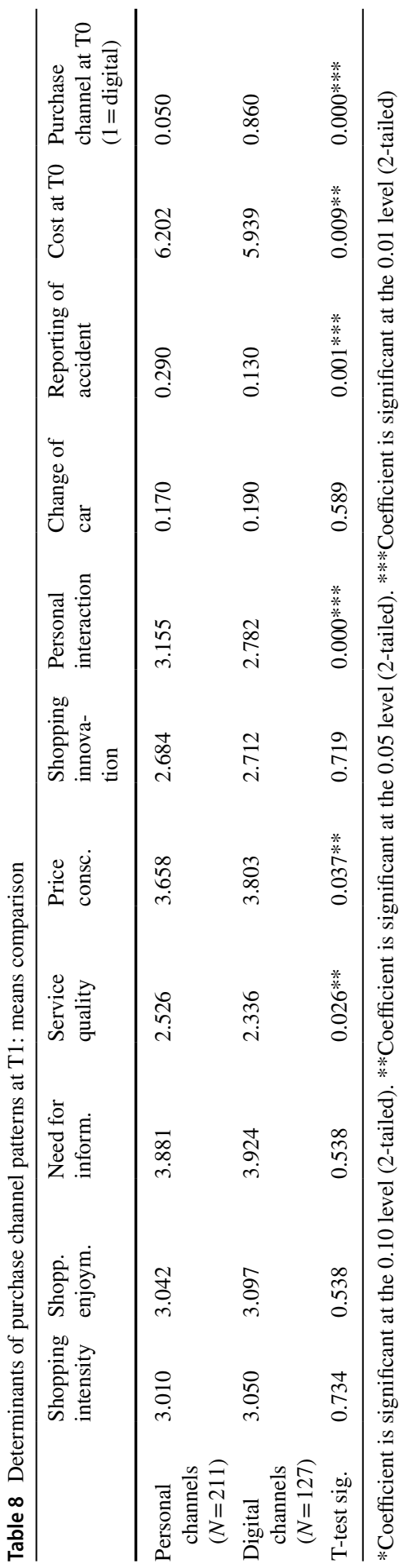


In turn, search patterns are not significantly affected by the customers' need for service quality and by price consciousness. The first lack of association (with service quality) isn't reflecting a low absolute importance of service quality, butrather-the generalized expectation of customers to receive a high service quality on each and every channel, be it personal or digital. Instead, the lack of association of search patterns with price consciousness levels, underlines this variable's key role in orienting the purchase channel choices, rather than the search patterns. In other words, a price-conscious customer may actively search through multiple channels so to obtain the needed information, but will eventually purchase on the channel that better matches its price targets. When combining the search and the purchase patterns, our results shed further light on the service industry's peculiar webrooming effects: based on the collected evidence, these behaviours appear to be significantly associated with the customers' preference for service quality and for personal interaction (which can mostly be satisfied on the offline, personal channels). Furthermore, our results show that a significant explanatory variable of the purchase channel decisions is also represented by the purchase channel choices made in the previous period (T0), thus highlighting a very strong purchase channel synergy at the temporal level.

The above findings confirm and advance the previous studies on multiple channel search (Verhoef et al. 2007) and webrooming effects (Flavian et al. 2016), and enlarge our knowledge of the determinants of the multi- and monochannel search behaviours, particularly at the psychographic level. More in general, these results shed further light on our understanding of channel choices of contractualized individual services. Due to the length and complexity of these services' customer journeys (encompassing several phases, from information search to purchase and after-purchase interactions), their typical indefinite duration (as a consequence of periodical renewals), the extended pre- and post-purchase interactions, and the significant channel synergy effects, this research confirms that a variety of determinants will eventually exert an influence on customer behaviours and channel choices.

Our results have significant implications for contractualized service providers' strategies: instead of just focusing on the channels where most of the purchases are finalized (i.e., the traditional offline channels), to align with customer's expectations, providers shall offer their customers broad search and purchasing options, leveraging on all the channels available, and seamless channel transition opportunities, so to exploit all the available synergies along the service relationships. In sum, retailers shall provide customers with an integrated shopping journey, where channel decisions are aligned to the provider's retail strategies, the customers' experience and the expected shopping performance, and not left to the individual initiative of customers (Homburg et al. 2017). Our findings also show the possibility for contractualized service providers to rethink the way they profile and segment their customers, based on our classification of search patterns and determinants. Further, in an attempt to optimize their multichannel strategy, providers shall intervene on the channel ownership structure, the channel branding, the information available, the assortment of services and the customer service level on each channel. In particular, they shall encourage their offline stores in developing positive synergies with the digital channels (Hu and Tracogna 2020). 
As most research, this too suffers from some limitations, starting from our convenience sample (composed of Masters' and MBA graduates), which doesn't reflect the general population profile of service users, due to the different levels of education, age range, disposable income and knowledge of the service (a number of interviewees hold a degree in insurance). A further specific limitation of the sample refers to the different nationalities and countries of residence of the interviewed customers. Indeed, while we can expect that such dimensions may have a relevant impact on the search patterns and on the channel choices (because of the different cultural habits and levels of channel evolution in different countries), unfortunately we could not explore this matter due to the limited number of sampled customers and the sample's unbalanced geographic stratification. Further limitations pertain to the empirical field of study (motor insurance) which may be only partially representative of the whole contractualized individual services category, thus limiting the generalizability of our results. Additionally, our study mostly focuses on two phases of the service shopping journey: the pre-purchase information search and the purchase decision. Although we have considered two successive periods (T0 and T1) and have included, as control variables, a number of conditions pertaining to the post-purchase phase in T0 (e.g., the reporting of a car accident), a more integrated analysis of the whole service relationship, including a focus on the channels where the post-purchase interactions take place, should be included in future research. This also leads to another limitation, pertaining to the methodology utilized: compared to this cross-sectional study, a panel-based study would be better aligned to the relational and processual nature of the contractualized services' shopping journeys, although at the cost of a more difficult implementation. Another limitation refers to our channel classification (personal and digital) and to the difficul application of such classification to the digital social networks channel. This may be potentially problematic for other research purposes, and we are aware the matter shall be approached with a lot of attention in future research, also by distinguishing the different types of digital social networks and their different attitudes in supporting the customers' shopping journeys. As a last limitation, it is to be noted that this research was aimed at describing the patterns and determinants of multichannel search and purchase choices (with a focus on webrooming behaviours) and not to assess the impact of such choices and behaviours on the service provider's financial performance and on the service customer loyalty. Future research could further explore the matter, also in reference to the different services within the contractualized services category.

Funding Open access funding provided by Università degli Studi di Trieste within the CRUI-CARE Agreement.

Data availability All collected data and data analysis procedures are available to any interested parties, upon request to the Authors.

\section{Declarations}


Conflict of interest The Authors report no conflicts of interest and/or competing interests.

Open Access This article is licensed under a Creative Commons Attribution 4.0 International License, which permits use, sharing, adaptation, distribution and reproduction in any medium or format, as long as you give appropriate credit to the original author(s) and the source, provide a link to the Creative Commons licence, and indicate if changes were made. The images or other third party material in this article are included in the article's Creative Commons licence, unless indicated otherwise in a credit line to the material. If material is not included in the article's Creative Commons licence and your intended use is not permitted by statutory regulation or exceeds the permitted use, you will need to obtain permission directly from the copyright holder. To view a copy of this licence, visit http://creativecommons.org/licen ses/by/4.0/.

\section{References}

Alba, J., Lynch, J., Weitz, B., Janiszewski, C., Lutz, R., Sawyer, A., and Wood, S. (1997). Interactive home shopping: consumer, retailer, and manufacturer incentives to participate in electronic marketplaces. Journal of Marketing, 61(3), 38-53. https://doi.org/10.1177/002224299706100303

Arora, S., \& Sahney, S. (2019). Examining consumers' webrooming behavior: An integrated approach. Marketing Intelligence and Planning, 37(3), 339-354. https://doi.org/10.1108/ MIP-05-2018-0152

Baker, J., Parasuraman, A., Grewal, D., \& Voss, G. B. (2002). The influence of multiple store environment cues on perceived merchandise value and patronage intentions. Journal of Marketing, 66(2), 120-141. https://doi.org/10.1509/jmkg.66.2.120.18470

Balasubramanian, S., Raghunathan, R., \& Mahajan, V. (2005). Consumers in a multichannel environment: product utility, process utility, and channel choice. Journal of Interactive Marketing, 19(2), 12-30. https://doi.org/10.1002/dir.20032

Barwitz, N., \& Maas, P. (2018). Understanding the omnichannel customer journey: Determinants of interaction choice. Journal of Interactive Marketing, 43, 116-133. https://doi.org/10.1016/j. intmar.2018.02.001

Beck, N., \& Rygl, D. (2015). Categorization of multiple channel retailing in multi-, cross-, and omnichannel retailing for retailers and retailing. Journal of Retailing and Consumer Services, 27, 170-178. https://doi.org/10.1016/j.jretconser.2015.08.001

Bell, D. R., Gallino, S., \& Moreno, A. (2014). How to win in an omnichannel world. MIT Sloan Management Review, 56, 45-53.

Bell, D. R., Gallino, S., \& Moreno, A. (2017). Offline showrooms in omnichannel retail: Demand and operational benefits. Management Science, 64(4), 1629-1651. https://doi.org/10.1287/ mnsc.2016.2684

Bühler, P., Eling, M., Maas, P., \& Milanova, V. (2016). The consumer's view of consumer protection: An empirical study of the swiss insurance market. Institute of Insurance Economics.

Chiou, J. S., \& Pan, L. Y. (2009). Antecedents of internet retailing loyalty difference between heavy versus light shoppers. Journal of Business and Psychology, 24, 327-339. https://doi.org/10.1007/ s10869-009-9111-7

Chiu, H. C., Hsieh, Y. C., Roan, J., Tseng, K. J., \& Hsieh, J. K. (2011). The challenge for multichannel services: cross-channel free riding behaviour. Electronic Commerce Research and Applications, 10(2), 268-277. https://doi.org/10.1016/j.elerap.2010.07.002

Cho, S., \& Workman, J. (2011). Gender, fashion innovativeness and opinion leadership, and need for touch: effects on multi-channel choice and touch/non-touch preference in clothing shopping. Journal of Fashion Marketing and Management, 15(3), 363-382. https://doi.org/10.1108/13612 021111151941

Choi, J., \& Park, J. (2006). Multichannel retailing in Korea: Effects of shopping orientations and information seeking patterns on channel choice behaviour. International Journal of Retail \& Distribution Management, 34, 577-596. https://doi.org/10.1108/09590550610675912

Chou, S. Y., Shen, G. C., Chiu, H. C., \& Chou, Y. T. (2016). Multichannel service providers' strategy: understanding customers' switching and free-riding behaviour. Journal of Business Research, 69(6), 2226-2232. https://doi.org/10.1016/j.jbusres.2015.12.034 
Choudhury, V., \& Karahanna, E. (2008). The relative advantage of electronic channels: A multidimensional view. MIS Quarterly, 32(1), 179-200. https://doi.org/10.2307/25148833

Crosby, L. A., Evans, K. R., \& Cowles, D. (1990). Relationship quality in services selling: An interpersonal influence perspective. Journal of Marketing, 54(3), 68-81. https://doi. org/10.2307/1251817

Dabholkar, P. A. (1996). Consumer evaluations of new technology-based self-service options: An investigation of alternative models of service quality. International Journal of Research in Marketingt, 13(1), 29-51. https://doi.org/10.1016/0167-8116(95)00027-5

Dabholkar, P. A., \& Bagozzi, R. P. (2002). An attitudinal model of technology-based self-service: Moderating effects of consumer traits and situational factors. Journal of the Academy of Marketing Science, 30(3), 184-201. https://doi.org/10.1177/0092070302303001

Flavian, C., Gurrea, R., \& Orus, C. (2016). Choice confidence in the webrooming purchase process: The impact of online positive reviews and the motivation to touch. Journal of Consumer Behaviour, 15(5), 459-476. https://doi.org/10.1002/cb.1585

Flavian, C., Gurrea, R., \& Orús, C. (2019). Feeling confident and smart with webrooming: understanding the consumer's path to satisfaction. Journal of Interactive Marketing, 47, 1-15. https://doi. org/10.1016/j.intmar.2019.02.002

Flavian, C., Gurrea, R., \& Orús, C. (2020). Combining channels to make smart purchases: The role of webrooming and showrooming. Journal of Retailing and Consumer Services, 52, 101923. https:// doi.org/10.1016/j.jretconser.2019.101923

Florenthal, B., \& Shoham, A. (2010). Four-mode channel interactivity concept and channel preferences. Journal of Services Marketing, 24(1), 29-41. https://doi.org/10.1108/0887604101101787141

Fornari, E., Fornari, F., Grandi, S., Menegatti, M., \& Hofacker, C. F. (2016). Adding store to web: Migration and synergy effects in multi-channel retailing. International Journal of Retail \& Distribution Management, 44(6), 658-674. https://doi.org/10.1108/IJRDM-07-2015-0103

Fornell, C., \& Larcker, D. F. (1981). Evaluating structural equation models with unobservable variables and measurement error. Journal of Marketing Research, 18, 39-50. https://doi.org/10.1177/00222 4378101800104

Forsythe, S., Liu, C., Shannon, D., \& Gardner, L. C. (2006). Development of a scale to measure the perceived benefits and risks of online shopping. Journal of Interactive Marketing, 20(2), 55-75. https:// doi.org/10.1002/dir.20061

Frasquet, M., \& Miquel, M.-J. (2017). Do channel integration efforts pay-off in terms of online and offline customer loyalty? International Journal of Retail \& Distribution Management, 45(7/8), 859-873. https://doi.org/10.1108/IJRDM-10-2016-0175

Gensler, S., Leeflang, P., \& Skiera, B. (2012). Impact of online channel use on customer revenues and costs to serve: Considering product portfolios and self-selection. International Journal of Research in Marketing, 29(2), 192-201. https://doi.org/10.1016/j.ijresmar.2011.09.004

Goldsmith, R. E., \& Hofacker, C. F. (1991). Measuring consumer innovativeness. Journal of the Academy of Marketing Science, 19(3), 209-221. https://doi.org/10.1177/009207039101900306

Hair, J. F., Hult, G. T. M., Ringle, C., \& Sarstedt, M. (2016). A primer on partial least squares structural equation modelling (PLS-SEM) (2nd ed.). Sage.

Homburg, C., Jozic, D., \& Kuehnl, C. (2017). Customer experience management: Toward implementing an evolving marketing concept. Journal of the Academy of Marketing Science, 45(3), 377-401. https ://doi.org/10.1007/s11747-015-0460-7

Hoque, A. Y., \& Lohse, G. L. (1999). An information search cost perspective for designing interfaces for electronic commerce. Journal of Marketing Research, 36(3), 387-394. https://doi. org/10.1177/002224379903600307

Hu, T. I., \& Tracogna, A. (2020). Multichannel customer journeys and their determinants: Evidence from motor insurance. Journal of Retailing and Consumer Services, 54, 102022. https://doi.org/10.1016/j. jretconser.2019.102022

Insurance Europe (2019). European insurance. Key facts

Insurance Information Institute (2020). Insurance fact book

Juaneda-Ayensa, E., Mosquera, A., \& Sierra Murillo, Y. (2016). Omnichannel customer behaviour: Key drivers of technology acceptance and use and their effects on purchase intention. Frontiers in psychology, 7, 1-11. https://doi.org/10.3389/fpsyg.2016.01117,1117

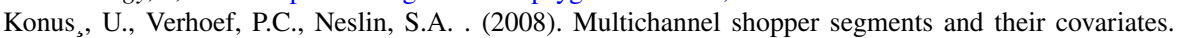
Journal of Retailing, 84(4), 398-413. https://doi.org/10.1016/j.jretai.2008.09.002 
Kumar, V., \& Venkatesan, R. (2005). Who are the multichannel shoppers and how do they perform? correlates of multichannel shopping behaviour. Journal of Interactive Marketing, 19(2), 44-62. https:// doi.org/10.1002/dir.20034

Lee, H., \& Kim, J. (2008). The effects of shopping orientations on consumers'esatisfaction with product search and purchases in a multi-channel environment. Journal of Fashion Marketing and Management, 12(2), 193-216. https://doi.org/10.1108/13612020810874881

Lewis, J., Whysall, P., \& Foster, C. (2014). Drivers and technology-related obstacles in moving to multichannel retailing. International Journal of Electronic Commerce, 18(4), 43-68. https://doi. org/10.2753/JEC1086-4415180402

Lichtenstein, D. R., Netemeyer, R. G., \& Burton, S. (1990). Distinguishing coupon proneness from value consciousness: An acquisition-transaction utility theory perspective. Journal of Marketing, 54(3), 54-67. https://doi.org/10.1177/002224299005400305

Liu, H., Lobschat, L., Verhoef, P. C. (2018). Multichannel retailing: a review and research agenda. Now Publishers Incorporated.

Lovelock, C. H. (1983). Classifying services to gain strategic marketing insights. Journal of Marketing, 47(3), 9-20.

Malhotra, A., \& Kubowicz-Malhotra, C. (2013). Exploring switching behavior of US mobile service customers. Journal of Services Marketing, 27(1), 13-24. https://doi.org/10.1108/0887604131 1296347

McGoldrick, P. J., \& Collins, N. (2007). Multichannel retailing: Profiling the multichannel shopper. The International Review of Retail, Distribution and Consumer Research, 17(2), 139-158. https ://doi.org/10.1080/09593960701189937

Midgley, D. F., \& Dowling, G. R. (1978). Innovativeness: The concept and its measurement. Journal of Consumer Research, 4(4), 229-242. https://doi.org/10.1086/208701

Neslin, S. A., Grewal, D., Leghorn, R., Shankar, V., Teerling, M. L., Thomas, J. S., \& Verhoef, P. C. (2006). Challenges and opportunities in multichannel customer management. Journal of Service Research, 9(2), 95-112. https://doi.org/10.1177/1094670506293559

Nunnally, J. C., \& Bernstein, I. H. (1994). Psychometric theory (3rd ed.). McGraw-Hill.

Parasuraman, A., Zeithaml, V. A., \& Berry, L. L. (1988). SERVQUAL: A multiple-item scale for measuring consumer perceptions of service quality. Journal of Retailing, 64(1), 12-40.

Pauwels, K., Leeflang, P. S. H., Teerling, M. L., \& Huizingh, K. R. E. (2011). Does online information drive offline revenues? only for specific products and consumer segments! Journal of Retailing, 87(1), 1-17. https://doi.org/10.1016/j.jretai.2010.10.001

Piercy, N. (2012). Positive and negative cross-channel shopping behaviour. Marketing Intelligence and Planning, 30(1), 83-104. https://doi.org/10.1108/02634501211193930

Piotrowicz, W., \& Cuthbertson, R. (2014). Introduction to the special issue information technology in retail: Toward omnichannel retailing. International Journal of Electronic Commerce, 18(4), 5-16. https://doi.org/10.2753/JEC1086-4415180400

Rangaswamy, A., \& Van Bruggen, G. H. (2005). Opportunities and challenges in multichannel marketing: An introduction to the special issue. Journal of Interactive Marketing, 19(2), 5-11. https ://doi.org/10.1002/dir.20037

Ratchford, B. T., Talukdar, D., \& Lee, M.-S. (2001). A model of consumer choice of the internet as an information source. International Journal of Electronic Commerce, 5(3), 7-21. https://doi. org/10.1080/10864415.2001.11044217

Rippé, C. B., Sussan, F., Yurova, Y., \& Weisfeld-Spolter, S. (2015). Is there a global multichannel consumer? International Marketing Review, 32(3/4), 329-349. https://doi.org/10.1108/ IMR-10-2013-0225

Saghiri, S. S., Bernon, M., Bourlakis, M., \& Wilding, R. (2018). Omni-channel logistics special issue. International Journal of Physical Distribution \& Logistics Management, 48(4), 362-364. https:// doi.org/10.1108/IJPDLM-05-2018-361

Schroder, H., \& Zaharia, S. (2008). Linking multi-channel customer behaviour with shopping motives: An empirical investigation of a German retailer. Journal of Retailing and Consumer Services, 15(6), 452-468. https://doi.org/10.1016/j.jretconser.2008.01.001

Schoenbachler, D. D., \& Gordon, G. L. (2002). Multi-channel shopping: Understanding what drives channel choice. Journal of Consumer Marketing, 19(1), 42-53. https://doi.org/10.1108/07363 760210414943 
Stone, M., Hobbs, M., \& Khaleeli, M. (2002). Multichannel customer management: The benefits and challenges. Journal of Database Marketing \& Customer Strategy Management, 10, 39-52. https ://doi.org/10.1057/palgrave.jdm.3240093

Venkatesan, R., Kumar, V., \& Ravishanker, N. (2007). Multichannel shopping: Causes and consequences. Journal of Marketing, 71(2), 114-132. https://doi.org/10.1509/jmkg.71.2.114

Verhoef, P. C., Neslin, S. A., \& Vroomen, B. (2007). Multichannel customer management: Understanding the research-shopper phenomenon. International Journal of Research in Marketing, 24(2), 129-148. https://doi.org/10.1016/j.ijresmar.2006.11.002

Verhoef, P. C., Kannan, P. K., \& Inman, J. J. (2015). From multi-channel retailing to omni-channel retailing: Introduction to the special issue on multi-channel retailing. Journal of Retailing, 91(2), 174-181. https://doi.org/10.1016/j.jretai.2015.02.005

Weinberg, B. D., Parise, S., \& Guinan, P. J. (2007). Multichannel marketing: Mindset and program development. Business Horizons, 50(5), 385-394. https://doi.org/10.1016/j.bushor.2007.04.002

Wind, Y., \& Mahajan, V. (2002). Convergence marketing. Journal of Interactive Marketing, 16(2), 64-79. https://doi.org/10.1002/dir.10009

Wollenburg, J., Holzapfel, A., Hübner, A., \& Kuhn, H. (2018). Configuring retail fulfilment processes for omni-channel customer steering. International Journal of Electronic Commerce, 22, 540-575. https ://doi.org/10.1080/10864415.2018.1485085

Yurova, Y., Rippé, C. B., Weisfeld-Spolter, S., Sussan, F., \& Arndt, A. (2017). Not all adaptive selling to omni-consumers is influential: The moderating effect of product type. Journal of Retailing and Consumer Services, 34, 271-277. https://doi.org/10.1016/j.jretconser.2016.01.009

Zhang, J., Farris, P. W., Irvin, J. W., Kushwaha, T., Steenburgh, T. J., \& Weitz, B. A. (2010). Crafting integrated multichannel retailing strategies. Journal of Interactive Marketing, 24(2), 168-180. https ://doi.org/10.1016/j.intmar.2010.02.002

Publisher's Note Springer Nature remains neutral with regard to jurisdictional claims in published maps and institutional affiliations. 